JOURNAL OF HEALTH SCIENCE AND PREVENTION

http://jurnalfpk.uinsby.ac.id/index.php/jhsp

ISSN 2549-919X (e)

\title{
Breastfeeding Practices during Pregnancy from the Perspective of Women in Makassar City
}

\author{
Bestfy Anitasari ${ }^{1 *}$, Imami Nur Rachmawaty ${ }^{2}$, Henny Permatasari ${ }^{3}$ \\ 1) Nursing Department of STIKES Kurnia Jaya Persada Palopo \\ 2) Maternity Nursing Department of Universitas Indonesia \\ 3) Community Nursing Department of Universitas Indonesia \\ ephyanto@yahoo.com \\ DOI: http://doi.org/10.29080/ihsp.v3i3S.273
}

\section{Kata Kunci}

Breastfeeding

During

Pregnancy;

Perspective;

Woman.

\begin{abstract}
Abstrak
The practice of breastfeeding during pregnancy is mostly done by women, including in Indonesia. Previous research has reported inconsistencies. Some people claim that this practice is beneficial and others report the risk among mothers, fetus, and breastfed children. The aim of this study is to interpret the practice of breastfeeding during pregnancy from a woman perspective. This study used interpretative phenomenology design with in-depth interviews with seven participants selected purposively. Data were analyzed using the Van Manen analysis stage and 11 themes were obtained. In general, mothers who breastfeed during pregnancy experienced a dilemma between fulfilling the child's right to breast milk and the desire to stop breastfeeding.
\end{abstract}

\section{Introduction}

The target set by the MDGs is to reduce infant mortality by 2/3 from 1990 to 2015 [1]. One of the efforts made is by giving the right food to the baby. Breastfeeding is the best way to provide optimal nutrition for babies because breast milk contains the best nutrition for baby's growth and development. However, based on existing data, the coverage of breastfeeding has decreased from year to year [2]. One of the failure factors in reaching the breastfeeding coverage is the presence of new pregnancy during breastfeeding $[3,4,5]$.

Breastfeeding and pregnancy are two separate processes and mutually exclusive by the steroid hormones. But conception can occur while breastfeeding [3]. Research by Shaaban and Glasier reported that $28.1 \%$ of mothers who breastfeed exclusively can still get pregnant [6]. Some women choose to wean their babies earlier, but some also choose to keep breastfeeding [3]. The practice of breastfeeding during pregnancy will have an impact on the health of pregnant women, the health of breastfed children, and the growth and development of the fetus, which continues until the baby is born. Kahn and Chien reported that pregnant and lactating women simultaneously experienced changes in body weight marked by a decrease in body mass index [7]. However, it is different from the results of research by Merchant, Martorell, and Haas who found that there was no weight loss in mothers who breastfed during pregnancy $[8,9]$.

A breastfed child when her mother is pregnant is likely to experience health problems. Marquis et al reported a weight loss in breastfed infants in pregnant women [10]. This happens because breastfeeding practices can affect the quality of breast milk, the amount of breast milk and the frequency of breastfeeding $[11,12,13,14]$. However, research conducted by Shaaban \& Glasier reported that $60.4 \%$ of breastfeeding children in pregnant women did not experience health problems [6]. Besides affecting the condition of a breastfed child, breastfeeding during pregnancy can also influence the fetus. The fetus has the potential to experience growth retardation because the condition of pregnancy, while breastfeeding presents a great risk for mothers to experience malnutrition if the nutrient consumption needed is inadequate [15]. However, this is contrary to the research results by Pareja who reported that the growth of fetuses born to mothers who breastfeed when pregnant do not experience interference. It is characterized by a baby's birth weight that is in accordance with his gestational age [16].

Other problems arising from breastfeeding mothers during pregnancy are such as abnormal uterine contractions, miscarriages, disorders of the uteroplacental circulation at the end of pregnancy, premature birth, labor dystocia, and fetal death in the womb $[3,6,10,17,18,19]$. However, different results were 
reported by Onwudiegwu who found that there was no negative impact on the development of pregnancy until the birth process and postpartum period in women who breastfed during pregnancy [20]. Breastfeeding during pregnancy has been carried out in various countries. Data in Indonesia regarding the number and how of breastfeeding during pregnancy carried out by mothers is not documented. From the results of the researchers' preliminary study, this phenomenon occurred in Makassar. However, this phenomenon continues to be studied about the safety of breast milk as a source of nutrition and also because there are still conflicting data related to the practice of breastfeeding during pregnancy. This is the reason for the importance of qualitative research to find out how to carry out the practice of breastfeeding during pregnancy from the perspective of pregnant women.

\section{Methods}

Interpretative phenomenology is the approach used in research. It explored how the phenomenon is obtained directly from participants who experienced it through an interaction built on mutual trust. Through the process of interpretation, it can be expressed the meaning of breastfeeding during pregnancy from the pregnant women's perspective so as to provide a deeper understanding of the phenomena.

Participants in this study were breastfeeding mothers during pregnancy who were selected using a purposive sampling technique based on the researcher objectives with certain considerations. In accordance with the researcher objectives, the participants involved in this study were seven people, three mothers when interviewed were not pregnant but had a history of breastfeeding during pregnancy and four mothers were pregnant and still breastfeeding their children during pregnancy. The mother has the following characteristics: healthy, knowing the pregnancy while breastfeeding, being able to share her experiences, can write and read and is willing to be a participant in this study. Participants involved in this study were selected in three ways, such as participants were obtained from data provided by the person in charge of the MCH program about mothers who had a distance between pregnancies of less than two years. The second was to wait for prospective participants at the public health center on the day of the pregnancy check-up. The third was the pregnant women having an examination were asked about the existence of other pregnant women who are breastfeeding or mothers who have a history of breastfeeding during pregnancy, both their neighbor or whom they know. In the process of selecting participants, the researcher, together with a key person, was a health care in charge of each public health center where the research was conducted. Data collection in this study used in-depth interviews with open questions and field notes to complete the interview. In-depth interviews with open-ended questions are done by using an interview guide. Other tools used were Sony's 2GB MP4 voice recording device and writing instruments. The stages of data analysis using the six-step analysis of Van Manen namely immersion, understanding, abstraction, synthesis, and theme development, illumination and illustration of phenomena, and integration and critique.

\section{Results}

This study has produced 11 themes that explain the meaning of breastfeeding during pregnancy which is summarized in the scheme as follows:

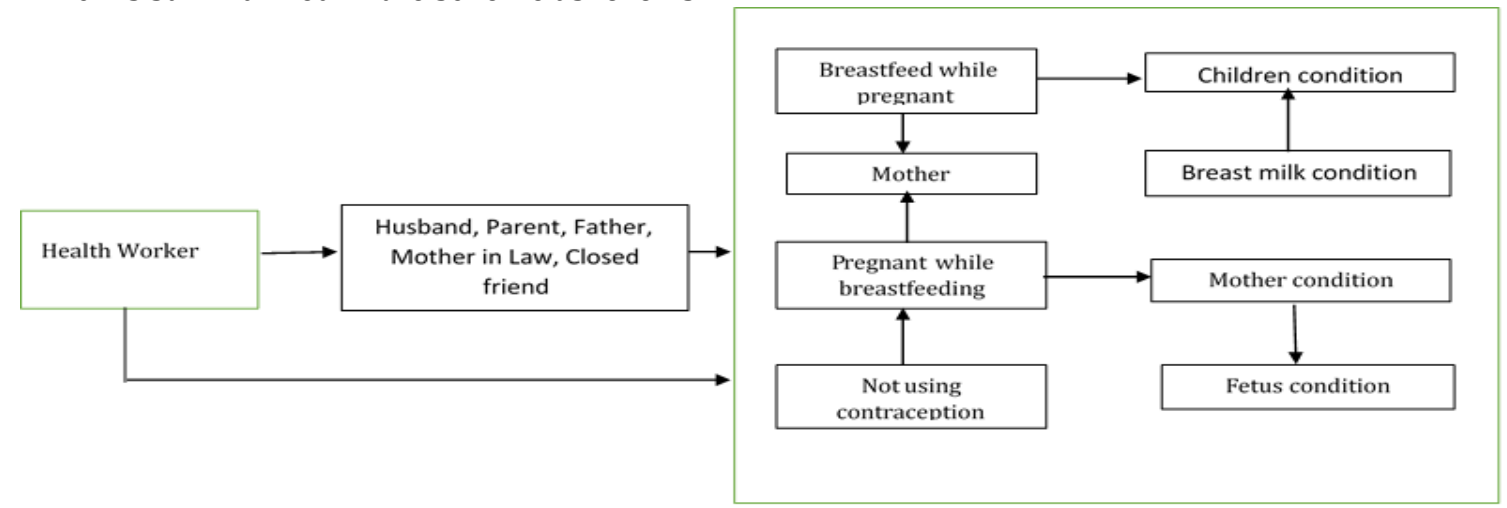

Scheme 1: The relationship between health workers, family, and nursing mothers during pregnancy

\section{The dilemma of breastfeeding mothers during pregnancy}

During pregnancy, breastfeeding mothers experience a dilemma between continuing to give breast milk as a child's right or weaning. The reason of the mothers to keep breastfeeding even though they are pregnant is to meet the needs of breastfeeding children who have not reached 2 years-old, breastfeeding is the right of children, children still want to breastfeeding, families cannot afford formula milk, hope the children to develop well, feel sorry for children and not at miscarriage risk. Like the following quote:

"Breastfeeding is the right of the child (participant 4)"

"That is the case because the child expects it (suckling), even though we have been bitterly stabbed here 
(holding the breast) but still continue (laugh) (participant 1) "

Some things are the reason for mothers to continue breastfeeding, but the desire of pregnant women related to the breastfeeding process is indicated by a variety of attitudes, such as unexpected to wean their babies, mothers desire to stop breastfeed, being forced to breastfeed and prioritizing pregnancy, such as the following quote:

"For me, if I am asked to be weaned, I just say I don't want (participant 7)"

"I just have to follow it (participant 2)"

Weaning efforts are carried out by participants and family members. The types of weaning are entrusted the child to the caregiver, reducing the intensity of breastfeeding, given the bottled milk, smearing the breast with bitter ingredients and forcing to stop breastfeeding forcefully, the following excerpt:

"I sometimes bitterly stabbed my nipples, usually balm, but they rub again and continue to suckle again... I smear something bad (looks thinking), but keep suckle (participant 1) "

\section{The condition of the mother and fetus during the breastfeeding process}

Pregnancy affects the condition of the mother and the condition of the fetus. Mothers feel discomfort in parts of the body, such as pain in the nipples, stomachache, dizziness, weakness, hunger after breastfeeding. Psychological discomfort such as confusion, worry about the condition of the fetus, trouble, disrupted activity, anger, and irritation. Psychological comfort is shown by being satisfied while breastfeeding and feeling healthier by breastfeeding. While the benefits of breastfeeding felt by pregnant women include breast milk to maintain the health of children, there is an inner bond if breastfeeding, breastfeeding makes children calm, more practical, mothers feel healthier and can rest while breastfeeding. The following is an example of a participant's quote:

"My nipple, pain like just breastfeeding after childbirth, that's what I feel (pointing to the breast) ... more pain I think (participant 2)"

"When the baby suckles, I feel satisfied, so I give, meet her needs right... I feel satisfied (participant 4)

"If you breastfeed while sleeping, it's even better because that's become our bedtimes (participant 1) "

The state of the fetus during breastfeeding is identified by three conditions, namely fetal growth according to gestational age, the birth of a normal baby and not knowing the condition of the fetus:

"When checked by ultrasound, the fetus is healthy and again in May checked by the ultrasound was still healthy ... All conditions are normal there is no physical problem and the doctor said that the baby's weight is normal, the size of the fetus in accordance with the age of pregnancy (participant 7)

\section{Impact of pregnancy on the process of Breastfeeding}

Pregnancy during breastfeeding affects the quality and quantity of breast milk. The more the gestational age increases, the milk production will decrease, the milk becomes white blood, runny, salty, and stale:

" When I breastfeed it may increase but the production is already less ... maybe not too much milk production at all, not too much as the beginning of childbirth ... because the production of breast milk is not too maximal especially may be in this pregnancy condition (participant 6) "

"It is a bit runny, not really tasty, and slightly salty taste (participant 3)"

\section{Child's condition during pregnancy}

The condition of the child during breastfeeding during pregnancy seems to be constantly hungry, suckling takes longer, the child is still asking for bottle milk, the child is crying and restless:

"The duration of breastfeeding is long, usually up to 1 hour. If the milk is usually much most 15-20 minutes but now longer suckle (participant 6)

\section{The attitude of other family members}

The indicated attitude by the husband, such as supporting to continue the breastfeeding, giving up the decision to breastfeed to the mother, and behaving normally. Parents' attitudes, among others, give up the decision to breastfeed to the mother, do not mind, forbid mothers to breastfeed, advises children to be weaned, treat the mother, help look after the grandchildren and give advice. Whereas the attitude of the surrounding people is generally opposed if pregnant women continue to breastfeed and seem to blame and ridicule pregnant women during breastfeeding:

"Such a husband also supports me to continue breastfeeding during pregnancy ... Husband said, "you know better". If it is safe with breastfeeding, continue (participant 4) "

"(parents) .. Give advice ... Say when you breastfeedyour child, you eat more, don't be lazy to eat (participants 5)"

"If they (neighbors) suggest to be weaned (participant 7) "

\section{The attitudes of health workers}

Attitude of health workers namely doctors support, doctors suggest weaning, doctors forbid, midwives forbid and midwives support. As an example of the following quote:

"She (midwife) is telling me, don't give any breast milk to the children because even sucking, the child doesn't have any contents to suck only blood (participant 3)" 


\section{Mother's desire for others}

Participants' hopes for family members include getting information, being motivated to continue breastfeeding, being served, and expected to be helped:

"With the contribution like ideas about how to boost the breast milk ... orya... what is the good food to boost it (participant 6) "

The mother's desire for health workers, such as, expected to get medicine from health workers, expected to get information from health workers, expected health checking, and food assistance:

"I was difficult to eat, so I expected to get supplement so that during pregnancy I can eat normally, but I don't get it (participant 7)"

Mother's eating habits when breastfeeding in a state of pregnancy

Mother's eating habits when breastfeeding in a state of pregnancy, namely rarely eating, being edacious, being lazy to eat, eating like before pregnancy, eating in small portion but frequent which supply more nutrients:

"I'm greedy ... I eat everything... every pregnant it must be strong to eat ... all my pregnancy was hearty, all of them I ate even when no breastfeeding ... the different food was just my cravings period ... usually the food was spicy, instant noodles, meatballs ... basically every pregnancy have different food cravings ... I guess anyway after breastfeeding my child (10th pregnancy) it seems like I want to eat more, I want to keep eating, after breastfeeding, eat again, wake up, eat again (participant 3) ".

\section{Mother's attitude towards others about breastfeeding}

The attitude shown by the participants is to stick to the stance to keep breastfeeding by trying to supply more nutrients and do not care about the reactions of the closest person who disagrees with the participant's decision to breastfeed:

"I don't care with what I will deserve, don't care if they want to be angry, I am okay with it (participant 2)" Unplanned Pregnancy

Pregnancy during breastfeeding is generally unplanned. Participants realized that if they did not have family planning, the chances of getting pregnant were very large. But they are not using contraception properly for several reasons, among others, the decision to do contraception handed over to the mother, following religious teachings, the husband does not want to participate using contraception, forgetting to use, has not use yet and is afraid to use and rarely meets with her husband:

"I cannot use that (injections and pills) because you see, my varicose fulfill until the thighs, the midwife said it will be getting worse (varicose veins) when using an injection or pill, so I am afraid to use... (participant 3) "

\section{Mother's attitude towards pregnancy}

An attitude reaction toward a new pregnancy are embarrassment due to the pregnancy, worrying and not ready to accept pregnancy, being grateful for pregnancy and accepting after some time:

"Getting pregnant is no longer a problem but very pleasant to have another child, even still breastfeeding, it's a gift from God, I can get pregnant quickly and have more children, my husband also said that when I was pregnant, I should be grateful (participant 4)) ".

\section{Discussion}

\section{The dilemma of Breastfeeding Mothers in the Period of Pregnancy}

The results of this study indicate that most mothers who breastfeed during pregnancy do not succeed in making decisions between continue the breastfeeding as a child's right to develop optimally and fulfill the desires of children while in the other hand, the mothers desire to stop breastfeeding because of the various risks she feels and also the absence of supporting factors that can strengthen the mother to continue breastfeeding during pregnancy. The results of this study found several things which are the reasons for pregnant women to continue breastfeeding, such as the condition of the child, the mother is not at risk of experiencing a miscarry age and the inability of the family to buy formula milk. The condition of the child is the main factor underlying the decision of most mothers to continue breastfeeding even though they are pregnant. This is consistent with the study results conducted by Oliveros et al. who found that the condition of children who still want to breastfeed, even though weaning efforts have been made is the reason for mothers to continue breastfeeding [21]. In this study, no participants reported contractions during breastfeeding. This is in accordance with the study results of Moscona \& Moore found that as many as $93 \%$ of pregnant women did not experience contractions during breastfeeding [11]. In addition, the family's socio-economic status can affect the ability of families to produce and or buy food [22].

In this study, mothers did not give formula milk because of minimal family financial conditions. Financial factors are one of the causes of women's inability to make decisions. Research conducted by Women development (2000) reveals that women's voices will not be heard in the family, especially if the woman does not support the family economy [23]. Judging from the hierarchy of decision making in the family, based on the research of Setyowati, women are at the lowest level. The main decision-makers are parents, parents-in-law, and husband [24]. 
Attitude is a factor that influences mother's decision making. Zhou et al found that the attitude of mothers who did not want to breastfeed was the most dominant factor in non-breastfeeding behavior [24]. However, in this study it was found that the attitude of mothers who do not want to breastfeed is not followed by their behavior to stop breastfeeding. The existence of this difference can be caused by the fact that the findings related to breastfeeding during pregnancy are still lack so that the information obtained by the mother is limited. According to Marquis and Huston, that the lack of fact findings obtained from authorized sources is an obstacle to appropriate decision making [13]. Many factors are the causes of women's helplessness in making decisions, including different gender influences in each culture where almost all cultures show that women have lower status than men [26].

Mothers with a positive view that breast milk when pregnancy are harmless, they are more likely to decide to continue breastfeeding, while those with a negative view choose to wean or at least attempt to wean $[3,27]$.The correct method of weaning is to reduce the frequency of breastfeeding gradually, avoid weaning children from breastfeeding into milk bottles, do not wean them suddenly and directly, do not deceive children by applying bitter ingredients such as herbs or coffee on the nipple or whatever makes it feels uncomfortable $[28,29,30]$. The results of this study indicate that weaning efforts carried out by mothers are dominated by incorrect weaning methods.

\section{The Impact of Breastfeeding Practices on Pregnancy}

This study found that all mothers experienced pain in the nipples that increase when the child suckled. Similar results were also found in Moscone \& Moore's study, increasing breast and nipple pain if the child suckling was the symptom of most complained by pregnant women when breastfeeding their babies and became a reason for mothers to wean [11. In this study also found that, mothers complained of nausea and vomiting were more severe than previous pregnancies in the first trimester of pregnancy at this time. The condition of nausea and vomiting aggravates the condition of mothers who breastfeed because it contributes to fatigue. The condition of fatigue affects the psychological condition of the mother. Mothers become more sensitive so they are often angry not only with their husbands but also with the breastfed children. The condition of pregnant women who still breastfeeding will cause irritability and increased emotional instability [3]. This study identified the presence of cramping symptoms accompanied by pain that propagates from the stomach during breastfeeding. This happens because the mother is lying on one side for a long time. According to Harsono, cramping usually occurs due to a tired body condition such as monotonous sleeping position [31].

\section{The Impact of Pregnancy on Breastfeeding}

The more gestational age increases, the breast milk stage changes automatically, namely from mature breast milk to colostrum followed by decreasing numbers [12]. The taste of colostrum is more saltier than riped milk. The taste of salt in breast milk occurs because of changes in the composition of breast milk during pregnancy, namely levels of sodium, potassium and increased protein levels while levels of lactose and glucose decrease. This taste change can make a child feel unhappy and wean themselves [13]. The change in breast milk was felt by participants in this study. The amount of breast milk is reduced which starts at the beginning of the second trimester of pregnancy characterized by deflated breasts. Another change occurs in breast milkthat is believed by participants is that the breast milk changes to white blood which is dangerous if consumed by children. Even though they experience changes, breast milk is still nutritionally complete and healthy for children to drink because while they are in the body, breast milk will never be stale [3]. For children who continue to suckle their mothers, they show changes in breastfeeding behavior, which tend to be hungry and suckle quickly for long time. In addition, children also still request formula milk after breastfeeding.

\section{Attitudes of Others}

The attitude shown by others towards the behavior of breastfeeding mothers were varies, ranging from supporting, giving up the decision to breastfeed, prohibiting or not showing a change in attitude. The attitude of others who support is manifested in behavior that can reduce the workload of the mother while those who do not support try to do weaning or suggest weaning. This study identifies sources of support obtained by breastfeeding mothers from husbands and parents. Similar findings were also found in Oliveros et al that support from husbands and parents were part of the reason for mothers to continue breastfeeding during pregnancy [21].

The biggest source of support for mothers is from their husbands [32]. This study found that husbands who support mothers for breastfeeding will help alleviate household work, one of which is taking over the role of caring for children, for example taking children for hang out, feeding children and making formula milk. However, there are also husbands who entrust the problem of baby care to their wives without participating as stated by Harwood [33]. Besides that, Rempel \& Rempel stated that husband's support in breastfeeding practice is very minimal, one of them is because culturally there is a division of roles where the father acts as breadwinner and household affairs including breastfeeding only by the wife without husband's intervention [32].

In Makassar community, patriarchal culture is still exists developing even though in customary law, husband and wife have the same position, but in practice women are still subordinate to men with 
positions and roles still revolving in domestic roles, which are only placed on things like households, kitchen, wells and mattresses [34]. In addition to husbands, parents and parent in-laws contribute to determining the duration of breastfeeding. This study founds that parents showed their support for mothers by cooking food favored by the mother, giving advice to more eat and helping to do other household chores. Whereas those who do not support suggest that the child should be weaned. The results of Barton study showed that participants who live in a house with a mother (grandmother) have a very large opportunity to do weaning [35].

Health workers are one source of support for mothers besides family. Health workers, namely doctors and midwives, reportedly opposed breastfeeding mothers during pregnancy assuming that by continuing breastfeeding the mother would experience a lot of physical and psychological stress [36]. All participants examined the pregnancy at the doctor and midwife, but the mother did not obtain accurate information about the practice of breastfeeding during pregnancy. This was revealed by the participants' desire to obtain information based on scientific evidence and in detail about the practice of breastfeeding during pregnancy.

\section{Unplanned Pregnancy}

The finding of this study that pregnancy occurs during breastfeeding is an unplanned pregnancy. There are various reasons for a woman to unexpected the presence of a child at a certain time in her life.

In a qualitative study of unsafe abortion, answers to the occurrence of unplanned pregnancies are obtained in married women who do not use contraception, especially for married women, the failure of contraception [37]. This study found that mothers did not use contraception because of various reasons including the decision to become a mother's responsibility, religious prohibition, husbands unwilling to participate in it, forgetting to use contraception related to the use of contraception pills which were methods that demanded compliance and high memory of the consumer. The reason for the long-term effects that could endanger health is a frightening specter for mothers to use contraception and have not had time to use because of lack of knowledge about contraceptive methods.

The occurrence of unplanned pregnancies is not entirely due to the unwillingness of mothers to use contraceptives, but the weak "power" of the mothers in making decisions using certain contraceptives makes mothers become objects that only follow what is recommended by others. If other people, in this case parents and husbands deter or do not approve of the mother using certain contraception, then usually the mother will follow the person's words. The lack of women's power to make decisions in determining and regulating the number of children is supported by research conducted by Asmi [38]. Although women in households have a large role in the economy, they are unable to make decisions especially in determining the number of children. This finding also proves the truth of the analysis by socialist feminists, which states that women remain subordinated even though they have a large role in economic resources as long aspatriarchal culture is still dominant [39].

\section{Conclusion and Suggestion}

Breastfeeding during pregnancy is a condition that makes the mother experience a dilemma between fulfilling the child's right to breastfeeding and the desire of mothers to stop breastfeeding because they prioritize maintaining their pregnancy compared to breastfeeding the child so that the mother is forced to breastfeed. The dilemma experienced by mothers as a manifestation makes the right decisions because of the lack of fact findings obtained information from health workers and also related to the position of mothers in the family as a subordinate.

Health workers are expected to be able to provide information about the condition of mothers who can continue breastfeeding during pregnancy and the impact of breastfeeding during pregnancy through health education or counseling, so that productive women who are pregnant and still breastfeeding can determine their attitude to continue breastfeeding or weaning.

\section{References}

1. Kementrian Negara Perencanaan Pembangunan Nasional/Kepala BPPN Republik Indonesia. Bincangbincang tentang MDGs 2015. Jakarta: Kementrian Negara Perencanaan Pembangunan Nasional/Kepala BPPN Republik Indonesia; 2008.

2. Badan Penelitian dan Pengembangan Kesehatan Kementerian Kesehatan RI. Riset kesehatan dasar (RISKESDAS) 2010. Jakarta: Kementerian Kesehatan RI; 2010.

3. Flower H. Adventures in tandem nursing: breastfeeding during pregnancy and beyond. La Leche League International : Schaumburg, Illinois; 2003.

4. Ingran J, Johnson DA. Feasibility study of a intervention to enhance family support for breastfeeding in a deprived area in Bristol, UK. Midwifery. 2004; 20:367-379.

5. Quan XZ, Yang HH, Zheng XH. An exploration of factors associated with breastfeeding behavior. Maternal Child Health Care China. 2005; 20:1305-1307.

6. Shaaban OM, Glasier AF. Pregnancy during breastfeeding in rural Egypt. Contraception. 2008; 77:350354. 
7. Kahn KS, Chien NF. Nutritional stress of reproduction. Acta Obstetric Gynecology Scand. 1998; 77:395401.

8. Merchant K, Martorell R, Haas J. Maternal and fetal responses to the stresses of lactation concurrent with pregnancy and of short recuperative intervals. American Journal Clinical Nutrition. 1990; 52:280-288

9. Merchant, K., Martorell, R., \& Haas, J. Consequences for maternal nutrition of reproductive stress across consecutive pregnancies. American Journal Clinical Nutrition. 1990; 52: 616-620

10. Marquis GS, Penny ME, Diaz JM, Marin RM. Postpartum consequences of an overlap of breastfeeding and pregnancy: reduced breast milk intake and growth during early infancy. Pediatrics. 2002; 109:1-8

11. Moscone S, Moore MJ. Breastfeeding during pregnancy. Journal Human Lactation. 1993; 9(2):83-88.

12. Moscone S, Moore MJ. An overlap of breastfeeding during late pregnancy is associated with subsequent changes in colostrum composition and morbidity rates among peruvian infants and their mothers. Community and International Nutrition. 2003; 13: 2585-2591

13. Marquis BL, Huston CJ. Leadership roles and management function in nursing. Theory \& Application. 4th edition. Philadelphia: Lippincott; 2003

14. Ismail SA, AM Abd-Ellah, AA Abd-El-Khair, Tammam AE. Study of probable effects of a new pregnancy on some milk constituents in lactating women. Research Journal of Medicine and Medical Science. 2009; 4(1):49-54.

15. King JC. The risk of maternal nutritional depletion and poor outcomes increases in early or closely spaced pregnancies. Journal of Nutrition. 2003; 133:1732S-1736S.

16. Pareja GR. The association between breastfeeding during late pregnancy and the occurrence of small for gestational age and prolonged active phase of labor among peruvian women. [Published thesis]. Nutritional Science. Iowa State University Ames:Iowa; 2007.

17. Nybo AM, Wohlfahrt J, Christens P, Olsen J, Melbye M. Maternal age and fetal loss: population based register linkage study. BMJ. 2000; 320:1708-1712.

18. El-Saadani S. High fertility does not cause spontaneous intrauterine fetal loss: the determinants of spontaneous fetal loss in Egypt. Social Biology. 2000; 47:218-243.

19. Ishii H. Does breastfeeding induce spontaneous abortion? Journal of Obstetrics and Gynaecology Research. 2009; 35:864-868.

20. Onwudiegwu U. Is breastfeeding during pregnancy harmful? Journal of Obstetrics and Gynaecology. 2000; 20:157-160.

21. Oliveros C, Marquis G, Bartolini R, Rudatskira E. Maternal lactation: a qualitative analysis of the breastfeeding habits and beliefs of pregnant women living in Lima, Peru. International Quarterly of Community Health Education. 1999; 18:415-434.

22. Hanson MB. Correlates of breastfeding in rural population. American Journal Health Behaviour. 2003; 27 (4):432-444.

23. Dwiyanto dkk. Seksualitas, kesehatan reproduksi dan ketimpangan gender. Jakarta: Pustaka Sinar Harapan bekerjasama dengan pusat kajian wanita UI dan the Ford Foundation. 2001.

24. Setyowati. The impact of village midwives and candies in improving nutritional of pregnant women in selected rural villages in two districs Banten province Indonesia: Longitudinal study. [Dissertation]. Makara Kesehatan. 2003; vol 14 (1):5-10.

25. Zhou Q Younger KM, Kearney JM. An exploration of the knowledge and attitudes towards breastfeeding among a sample of Chinese mothers in Ireland. BMC Public Health. 2010; 10: 722.

26. Fischman RJ, Wick JG, Koenig BA. The use of "sex" and "gender" to define and characterize meaningful differences between men and women in National Institutes of Health 1999, agenda for Research on Women's Health in the 21st century: Vol. 1. Washington: Office of Reseach on Women's Health; 1999.

27. Feldman S, Victoria BC. Nursing through pregnancy. New Beginnings. 2000; 17:116-118.

28. Li R, Fein SB, Chen J, Grummer-Strawn LM. Why mothers stop breastfeeding: mothers' self-reported reasons for stopping during the first year. Pediatrics. 2008; 122 Suppl 2:S69.

29. Maier AS, Chabanet C, Schaal B. Breastfeeding and experience with variety early in weaning increase infants' acceptance of new foods for up to two months. Clinical Nutrition. 2008; 27:849.

30. Judarwanto W. Cara penyapihan yang baik dan benar. 2009. Diperoleh dari www. indonesian breastfeeding network.com diunduh tanggal 12 September 2012.

31. Harsono S. Kapita selekta neurologi. Edisi kedua. Yogyakarta: Gadjah Mada University Press. 2003.

32. Rempel LA, Rempel J. The breastfeeding team: the role of involved fathers in the breastfeeding family. Journal Human Lactation. 2010 Dec 20

33. Harwood K. Intent of expecting fathers to encourage breastfeeding, perceptions of support and barriers to encouraging breastfeeding. [Dissertations \& Theses]. Nutrition and Health Sciences:Department of. University of Nebraska-Lincoln. 2011.

34. Said N. Tanah sebagai mahar dalam perkawinan studi kasus perempuan Suku Bugis-Makassar di Sulawsi Selatan yang menerima tanah pada waktu menikah. [Tesis]. Universitas Indonesia $\begin{array}{llll}\text { (dipublikasikan). } & 2001 . & \text { Diperoleh } & \text { dari }\end{array}$ 
http://lontar.ui.ac.id/opac/themes/libri2/detail.jsp?id=73370\&lokasi=lokal

35. Barton S. Infant feeding practices of low-income rural mother. American Journal of Maternal Child Nursing. 2001; 26(2):93-97.

36. Berg ML, Ball HL. Practices, advices and support regarding prolong breastfeeding: A desccriptive study from Sri Lanka. Journal of Reproductive and Infant Psychology. 2007; 77:1001-1012

37. Grimes D, Benson J, Singh S. Unsafe abortion: the preventable pandemic. Lancet. 2006; 368: 19081919.

38. Asmi. Hak reproduksi perempuan pada masyarakat matrilinial Minangkabau di pedesaan Provinsi Sumatra Barat (Studi kasus perempuan di desa Bulakan Tinggi, Kecamatan Perwakilan Situjuh, Kabupaten Lima Puluh Kota, Provinsi Sumatra Barat). 2004. Penelitian tidak diterbitkan. Program Kajian Wanita: Program Pascasarjana Universitas Indonesia.

39. Meutia. Partisipasi laki-laki dalam kesehatan reproduksi. 2008. Diperoleh 9 November 2012 dari http://www.menegpp.go.id 